\title{
Wound Inflammatory Cells after Cardiac Surgery and the Patients' Survival
}

\author{
J. A. Viljanto ${ }^{1}$, E. S. Löyttyniemi ${ }^{2}$, T. J. A. Savunen ${ }^{1}$ \\ ${ }^{1}$ Department of Surgery, Turku University Hospital, Turku, Finland \\ ${ }^{2}$ Department of Biostatistics, University of Turku, Turku, Finland \\ Email: ‘jouko.viljanto@fimnet.fi, eliisa.loyttyniemi@utu.fi, timo.savunen@tyks.fi
}

How to cite this paper: Viljanto, J.A., Löyttyniemi, E.S. and Savunen, T.J.A. (2016) Wound Inflammatory Cells after Cardiac Surgery and the Patients' Survival. Surgical Science, 7, 511-521.

http://dx.doi.org/10.4236/ss.2016.712068

Received: November 8, 2016

Accepted: December 18, 2016

Published: December 21, 2016

Copyright $\odot 2016$ by authors and Scientific Research Publishing Inc.

This work is licensed under the Creative Commons Attribution International License (CC BY 4.0).

http://creativecommons.org/licenses/by/4.0/

\begin{abstract}
Objective: To find out possible associations between wound inflammatory cell response and the patients' survival. Background: Several articles have written about the effects of single inflammatory cell types on wound healing but little is known about the interaction of these cells on survival. The methods used in this study have made possible this kind of exploration. Methods: One hundred patients, aged from 41 to 78 years, underwent open heart surgery in the years 1998-1999 and were studied by using the Cellstick device for harvesting wound inflammatory cells during the first 24 hours after surgery. The results of the differential count were computerized by using artificial neural network for obtaining wound inflammatory cell node (WICN). The patients were followed up for sixteen years or to the death. WICN values were compared with the patients' survival. Results: WICN reflects survival better than any single type of wound inflammatory cells alone $(\mathrm{HR}=3.1 ; \mathrm{p}=0.081$ for low/high WICN at 10 year survival). From several clinical characteristics diabetes only predicted shorter survival time $(\mathrm{HR}=5.5 ; \mathrm{p}=0.014$ for 10 year survival) better than WICN. Conclusion: These results support the view that regularly timed cell-to-cell ratios in wound inflammation, most often seen as high WICN, reflect beneficial survival. Instead, aberrant counts of inflammatory cells in the wounds lead to low WICN and often to the patients' shorter survival.
\end{abstract}

\section{Keywords}

Surgical Wounds, Inflammatory Cells, Survival

\section{Introduction}

Since long wound healing has been considered as a local phenomenon consisting 
of clotting, inflammation, proliferation and remodeling, an orchestrated and timely perfect series of events with partial overlapping [1] [2] [3]. Fetal wound healing only takes place with cellular regeneration and nearly without inflammation [4] [5].

Wound infliction initiates the healing cascade, after which extravasated blood constituents form a hemostatic plug. Within a few hours neutrophils begin to transmigrate across the endothelial cell wall of blood capillaries. Extravasation takes place through the following steps: margination and endothelial adhesion, migration across the endothelium and movement of the leukocytes within the tissue via chemotaxis. Cellular response to injury involves direct cell to cell and cell to matrix interactions together with soluble mediators. The balance between stimulating and inhibitory mediators as well as defined chronology is crucial. Inflammation regulates and paves the way for the next phases for tissue repair [6] [7].

Year after year new biochemical markers for evaluation of systemic postsurgical inflammation [8] have been discovered while the importance of wound site non-infectious inflammation has gained much less attention. Divergent opinions exist, whether all types of inflammatory cells are necessary to cover the whole phase of inflammation [8] and what are their roles when resolution begins [9] [10].

In this study local inflammatory cell response in sternotomy wounds at hour 24 post surgery has been compared with later outcome of these patients with special emphasis on the count of single cell types and their mutual cell to cell ratios. Some comparisons with the known determinants of postsurgical survival have been made.

\section{Patients and Methods}

This prospective study was approved by the Joint Commission on Ethics of the Turku University and the Turku University Central Hospital. All the patients gave a written informed consent. The clinical part containing preoperative assessment, surgery and postoperative care were performed within one year from March 1998 to March 1999 in the Department of Surgery, Turku University Hospital. Patients to be reoperated as well as urgent and emergency cases were excluded. Characteristics of one hundred patients included in the final series are presented in Table 1. According to the Cleveland preoperative risk stratification scoring system in cardiac surgery the score level for increased morbidity is 4 and increased mortality 6. In our material $90 \%$ of the patients had score level 3 or less. Most of the patients $(n=73)$ underwent coronary bypass surgery (CABG). Aortic and mitral valve procedures were performed in 13, combined valve and CABG in 7 and total repairs of the ascending aorta in 5 patients. Additionally one patient underwent the closure of atrial septal defect (ASD) and one the pulmonary vein resection [11]. The age of the patients at time of surgery ranged from 41 to 78 years, mean 63.2 years. 
Table 1. Demographic and clinical characteristics of the patients $(n=100)$. Counts and mean with range are presented.

\begin{tabular}{cc} 
Age, years, mean (range) & $63.2(41-78)$ \\
Males & 74 \\
Females & 26 \\
Hypertension (syst. $\geq 140 \mathrm{mmHg})$ & 74 \\
Diabetes (insulin or oral) & 7 \\
Smokers, current & 7 \\
BMI (kg/m $\left.{ }^{2}\right)$ & $27.2(20-41)$ \\
Renal disease, creatinine $>120 \mu \mathrm{mol} / \mathrm{l}$ & 10 \\
NYHA [14] & 69 \\
I - II & 31 \\
III - IV & \\
Pulmonary disease & 60 \\
0 - 1 & 40 \\
CLEVELAND Clinic score $[15]$ & 6 \\
\hline
\end{tabular}

BMI = body mass index; NYHA = New York Heart Association classification; CLEVELAND Clinic score = Preoperative risk stratification scoring system in cardiac surgery.

\subsection{Surgery}

The standard anesthesia was induced with midazolam hydrochloride (MidazolamHameln ${ }^{\oplus}$, Hameln Pharmaceuticals GmbH, Hameln, Germany) or propofol (Recofol ${ }^{\oplus}$, Leiras, Turku, Finland) and carried on with fentanyl citrate (Fentanyl ${ }^{\oplus}$, Orion Pharma, Espoo, Finland), midazolam hydrochloride and pancuronium (Pavulon ${ }^{\oplus}$, Organon Teknika, Oss, Netherlands). A standard sternotomy and conventional cardiopulmonary bypass (Stöckert SII ${ }^{\circledR}$, Stöckert Instrumente $\mathrm{GmbH}$, München, Germany) were used in all cases. Arterial line was placed in ascending aorta and sequential venous cannula in the right atrium appendix with a tip in the inferior cava and side holes in the right atrium. In the mitral valve surgery and ASD seclusion a separate caval cannulation was used. Cardioplegic solution was applied either antegradely through the cannula in the ascending aorta in the bypass surgery or retrogradely or combined with another cannula in sinus coronaries in the aortic valve surgery. In all cases crystalloid cardioplegia (modified St, Thomas II, temperature $4^{\circ} \mathrm{C}$ ) was used with an initial dose of $1000 \mathrm{ml}$. Additional doses was given when needed. In valve operations also topical cooling with ice slush was used. Moderate systemic hypothermia was the practice in all cases. Venting was carried out through the cardioplegic cannula or the separate cannula in the left ventricle in valve operations. All patients 
had systemic heparinization (Heparin LEO ${ }^{\circledast}$ Leo Pharma, Ballerup, Denmark) during the bypass. It was converted with protamine sulphate (Protamin ${ }^{\oplus}$ Leo Pharma, Ballerup, Denmark) after weaning of the cardiopulmonary bypass. Sternum was closed with three conventional figure of eight sternum wires or with four Sternaband devices (Sternaband ${ }^{\circledR}$ steinless steel, Stony Brook Surgical Innovations Inc., New York, USA). Periosteum and subcutaneous tissue were closed with interrupted absorbale sutures (Vicryl ${ }^{\circledR}$, polygalactin 910, Hamburg, Germany).

The skin was sutured with interrupted nonabsorbale monofilament sutures (Dermalon ${ }^{\oplus}$, nylon, Santo Domino, Rebpublica Dominicana). The mean operation time was 185 minutes (range 125 - 265) and the anesthesia time was 277 minutes (range 200 - 420), respectively. The mean aortic clamping time was 77 minutes (range 36 - 146) and the mean cardiopulmonary bypass time was 101 minutes (range 49 - 166). The stitches were removed 10 - 12 days after surgery.

\subsection{Cellstick Device}

The original model of the Cellstick device (Cellomeda Oy, Turku, Finland), initially named Cellstic-Cell ulose and Silastic-was first presented in 1975. The present form of the Cellstick device, purposed for wound healing studies in man and used in this study, was published in 1995 [12]. It consists of a standard size, self-reinforced silicone rubber tube with a $1.3 \times 1.3 \times 20 \mathrm{~mm}$ piece of regenerated pure, homogenous cellulose sponge inside the end to be inserted subcutaneously into the wound. The outer part of the tube was protected with an $\Omega$-formed tube of the same material. Its adhesive under surface served for fixing the Cellstick to the underlying skin.

Before closing of the skin wound the sponge-containing end of the tube was left subcutaneously between the wound edges. Now wound fluid with inflammatory cells could move in- and outwards according to the pressure changes in the wound space. At the same time a part of the fluid maintaining cells adhered to the sponge surface and cells with a migratory ability could invade deeper into the sponge.

Precisely 24 hours after Cellstick insertion it was drawn out of the wound and placed into a sterile lab tube for immediate further handling. By gentle rinsing through the inner tube with $1.0 \mathrm{ml}$ of RPMI-1640 solution and thereafter with a constant speed with $9.0 \mathrm{ml}$ of the same solution using a pump constructed for the purpose, the cells were detached from the sponge framework to form a wound cell suspension. Aliquots of 25,50,100, or $200 \mu \mathrm{L}$, depending on the total number of cells, were taken into Cytospin cuvettes (Shandon Elliot, Shandon Scientific Co. Ltd, London, UK) and centrifuged at $1000 \mathrm{rpm}$. for 7 minutes. After air-drying, the glass slides were fixed by immersing them in absolute methanol for 5 minutes and stained by the May-Grünwald-Giemsa method using an automatic staining apparatus (Shandon Elliot, Shandon Southern Instruments 
Ltd, Camberley, Surrey, UK). The results of the differential count of 200 arbitrary cells, made by an experienced lab nurse, were recorded for computerized analysis with artificial neural network [13]. Wound inflammatory cell node (WICN) thus obtained, and expressed as ranked node values on a scale from 1 to 100 , took into account all inflammatory cells on the basis of their mutual ratios. Neutrophils, lymphocytes, eosinophils, basophils, monocytes and macrophages were all included in the self-organizing model. The higher was the WICN value at $\mathrm{H} 24$ post surgery the more progressed was the regular wound inflammatory cell response measured as mutual cell-to-cell ratios.

The original number of patients was 106. Owing to occlusion or kinking of the Cellstick inner tube, which was found as strongly decreased number of inflammatory cells $(<5000 /$ specimen) four specimens had to be rejected. Autolysis of neutrophils caused by occasional delay until cell analysis was performed destroyed the specimens from two additional patients. The remaining series of one hundred patients, 74 men and 26 women were under control during the next sixteen years or until death.

\subsection{Statistical Methods}

Descriptive statistics are presented as counts, mean and standard deviation (sd) or range. Survival times were studied up to 5, 10 and 16 years (full follow-up). For analyses WICN was classified into two classes, less than 70 or $\geq 70$ to illustrate low and high level of WICN. WICN values were compared between diabetic and non-diabetic with one-way analysis of variance. Kaplan-Meier curves were drawn to study how one factor effects on survival and Wilcoxon test was performed for comparison. Cox's proportional hazard model was build up to study several factors at the same model (smoking, WICN as classified, BMI, earlier heart attack, serum creatinine, diabetes, systolic blood pressure). Hazard ratios with 95\% profile likelihood confidence intervals (CI) are presented from the analyses. Same model with individual cell types and without WICN was also performed. P-value less than 0.05 (two-tailed) was considered as statistically significant, p-values between 0.05 and 0.10 were considered as indicatively significant. All statistical analyses were conducted with SAS ${ }^{\circledast}$ for Windows (Version 9.3 and 9.4).

\section{Results}

The median follow-up time was 16.7 years (from 2 days to 17.6 years) until September $2015(n=51)$ or to the death $(n=49)$. The time and causes of death were obtained from the Statistics Finland. The causes of death of 49 patients were as follows: cardiovascular 39 (heart related 36), Alzheimer disease 5, malignancy 3 and alcohol intoxication 2. Owing to small number of these groups all- cause mortality was mainly used in statistical analyses.

From the total of one hundred patients 7 died during the first follow-up year, 
4 of them before the end of the first postoperative month. Four additional patients, a total of 11 died before the end of the first 5 year period, 19 before that of 10 years and 49 before the end of follow-up period of 16 years (Table 2).

To evaluate factors associating with postoperative survival after open heart surgery following characteristics were included in the model (Cox's proportional hazard model): smoking (yes/no), body mass index (BMI), earlier heart attack (yes/no), diabetes (yes/no), serum creatinine, systolic blood pressure, risk score classification according to NYHA [14] and CLEVELAND [15], and wound inflammatory cell node WICN $(<70, \geq 70)$.

A great majority of wound inflammatory cells at hour 24 were neutrophilic leukocytes (78.2(14.1))\% and lymphocytes (20.1(13.6))\%, followed by macrophages $(1.0(1.4)) \%$, eosinophils $(0.5(0.6)) \%$, basophils $(0.1(0.4)) \%$ and monocytes $(0.1(0.2)) \%$ with remarkable individual variation (Figures $1(\mathrm{a})-(\mathrm{d})$ ).

When investigating survival times, these individual cell types alone did not have any association with the survival times but all of them were valuable as a part of WICN.

Patients who died during the first year after surgery had WICN values from 11 to 66 , mean 40.4 . Instead all patients who received a WICN value $\geq 80$ survived longer than nine years.

After 5 years follow-up diabetes only (Table 3 ) showed a significant association with the length of survival ( $\mathrm{HR}=8.2,95 \% \mathrm{Ci} 1.6$ to $34.0, \mathrm{p}=0.005)$. WICN was the next in association with $\mathrm{p}=0.156$, better than any of the other clinical characteristics mentioned above $(\mathrm{p}>0.35)$.

Table 2. Wound inflammatory cell node (WICN) in relation to survival.

\begin{tabular}{|c|c|c|c|c|c|c|c|}
\hline \multirow{3}{*}{ WICN } & \multirow{3}{*}{ Total } & \multicolumn{6}{|c|}{ Follow-up time } \\
\hline & & \multicolumn{2}{|c|}{5 years } & \multicolumn{2}{|c|}{10 years } & \multicolumn{2}{|c|}{16 years } \\
\hline & & Dead & Alive & Dead & Alive & Dead & Alive \\
\hline$<70$ & 69 & 10 & 59 & 16 & 53 & 36 & 33 \\
\hline$\geq 70$ & 31 & 1 & 30 & 3 & 28 & 13 & 18 \\
\hline $7-100$ & 100 & 11 & 89 & 19 & 81 & 49 & 51 \\
\hline
\end{tabular}

Table 3. Wound inflammatory cell node (WICN) and survival in diabetic and nondiabetic patients.

\begin{tabular}{cccccccccc}
\hline & & \multicolumn{7}{c}{ Follow-up time } \\
\cline { 3 - 9 } WICN $^{*}$ & Diabetes & Total & \multicolumn{2}{c}{5 years } & \multicolumn{2}{c}{10 years } & \multicolumn{2}{c}{16 years } \\
\cline { 4 - 9 } & & & & Dead & Alive & Dead & Alive & Dead & Alive \\
\hline $37.6(28.0)$ & Yes & 7 & 3 & 4 & 3 & 4 & 7 & 0 \\
$55.7(25.4)$ & No & 93 & 8 & 85 & 16 & 77 & 42 & 51 \\
\hline
\end{tabular}

${ }^{*}$ Mean (sd). 


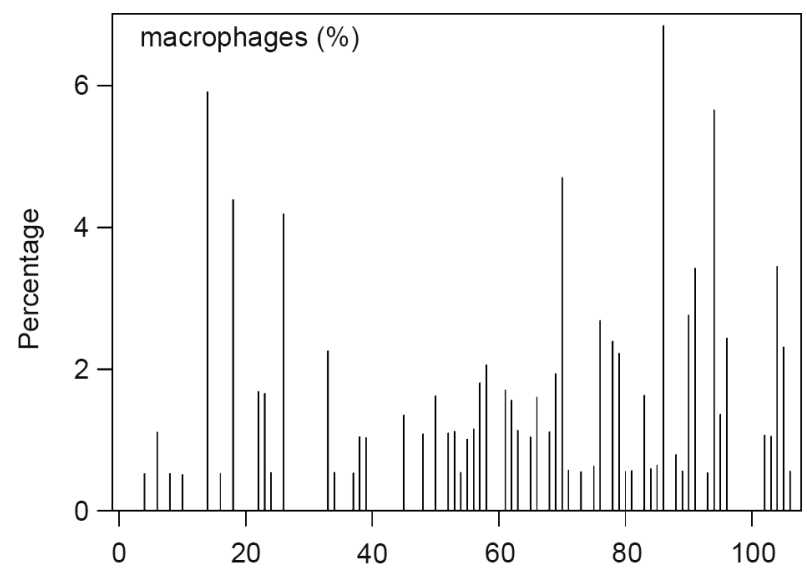

(a)

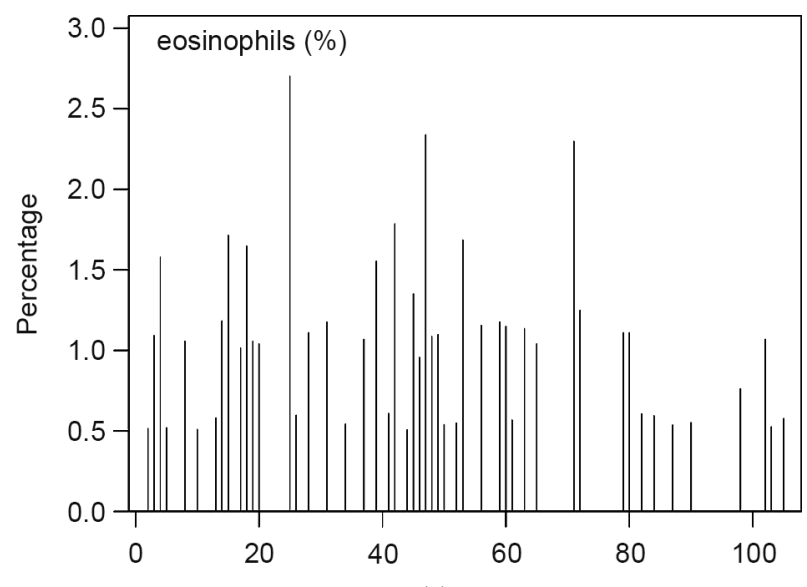

(c)

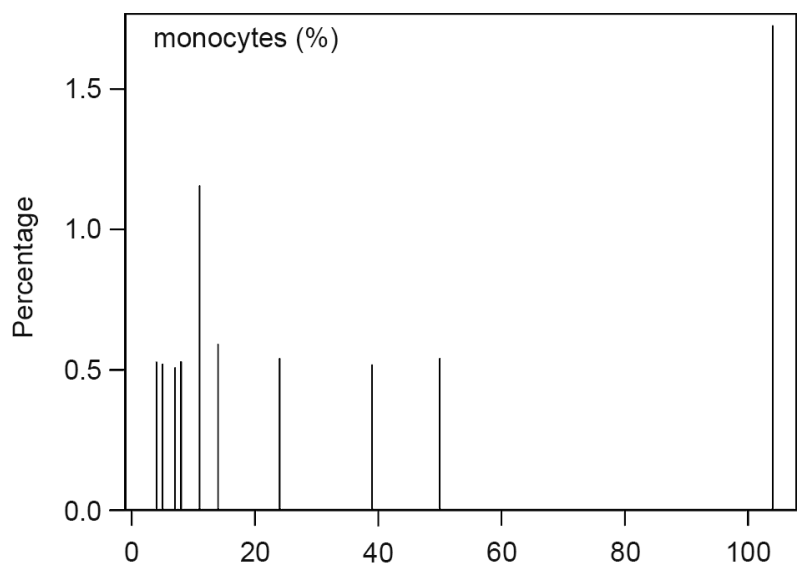

(b)

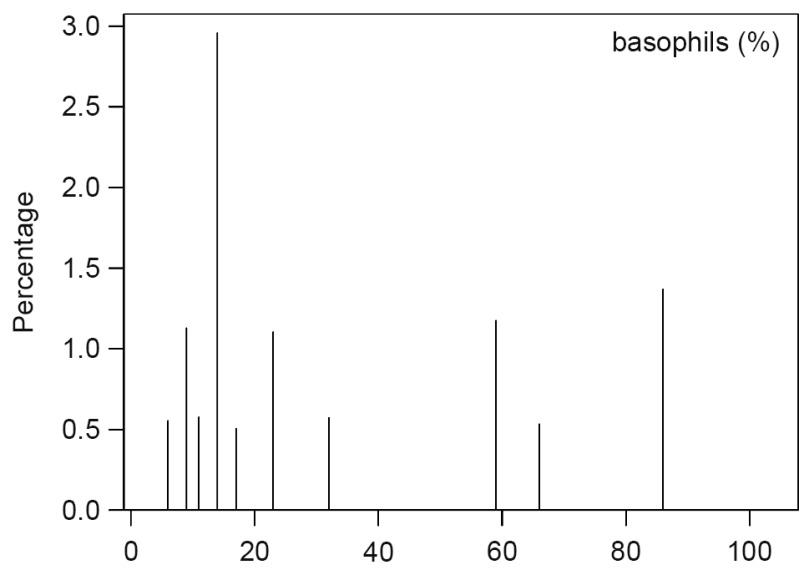

(d)

Figure 1. Distribution of wound inflammatory cells in Cellstick specimens observed in small percentage only. (a) Macrophages, (b) monocytes, (c) eosinophils and (d) basophils. Note different scale in percentage on the left and the serial number of the patients on the bottom line.

After 10 years follow-up diabetes continued to have a significant association with survival ( $\mathrm{HR}=5.5,95 \%$ CI 1.2 to $19.9, \mathrm{p}=0.014$ ) while WICN further had the second best value of $\mathrm{p}=0.081$ ( $\mathrm{HR}=3.1,95 \% \mathrm{CI} 0.99$ to 14.0$)$. None of the other factors did associate with the length of survival ( $\mathrm{p}>0.2)$.

After 16 years follow-up diabetes still had an association of $\mathrm{p}<0.001$ with survival, because all diabetic patients were dead. Association between WICN and survival was less than before $(\mathrm{p}=0.128)$. Other characteristics had no association in this patient series.

By using Kaplan-Meier method for survival analysis (Figure 2, Table 2) and a cut point of 70 on a ranked scale of WICN from 1 to 100 the upper third of nodes indicated a longer survival than patients with lower node values $(\mathrm{p}=$ 0.134 ). The difference remained nearly unchanged from the first postoperative year to the end of follow-up period with some reduction during the last few years.

Diabetes $(n=7)$ significantly decreased the values of WICN: mean 37.57 in diabetics vs 55.72 in non-diabetic $(n=93)$ patients $(p=0.073)($ Table 3$)$. 


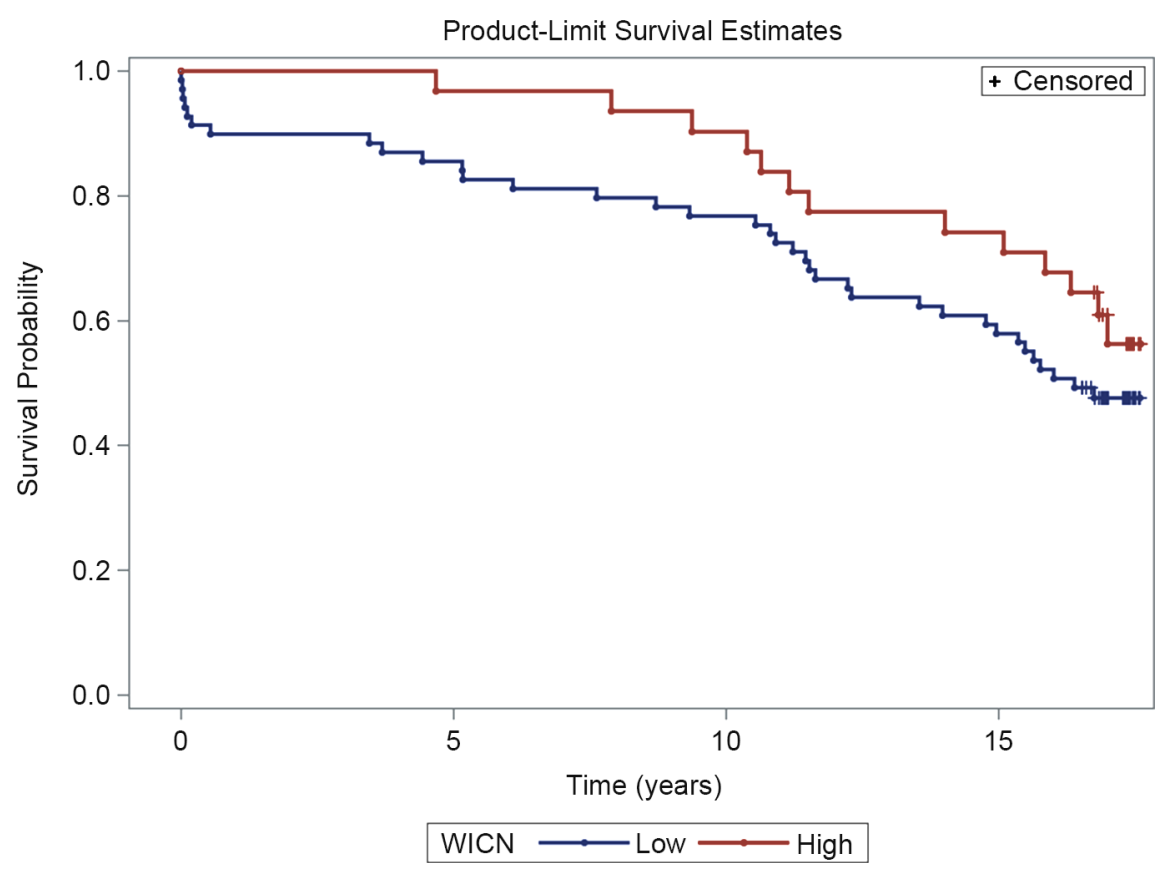

Figure 2. Kaplan-Meier survival curves. The upper curve describes patients with wound inflammatory cell node (WICN) values $\geq 70$ and the lower $<70$ ( $\mathrm{p}=0.13$, Wilcoxon test). Compare with Table 2.

Coronary atherosclerosis, verified in preoperative angiography, decreased WICN values. In CABG patients $(n=81)$ the mean of WICN values was 52.28 (26.52) whereas in valve surgery $(n=19) 63.68$ (21.13), respectively. The difference was indicatively significant $(\mathrm{p}=0.085)$.

\section{Discussion}

The magnitude of tissue damage in connection of routine surgery varies from small superficial incisions to large operations. Accordingly, local and systemic biochemical and cellular responses may be negligible or most extensive. Open cardiac surgery with cardiopulmonary bypass (CPB) belongs clearly to major procedures. Additional strengths are the uniform location, length and depth of the presternal skin incisions. CPB may activate the inflammatory response following exposure of blood to the foreign surfaces, through the ischemia-reperfusion injury and endotoxemia [16]. Hence in this study local individual inflammatory changes are strong enough to be detected.

In adults nonmicrobial postsurgical wound inflammation has a bright goal as an essential part of tissue repair. It begins soon after tissue injury, reaches the maximum intensity within two to three days and resolves thereafter in a few days to allow fibroblast proliferation. Lack in regular resolution may lead to healing disorders and chronic wounds.

Quite another thing is many usual chronic diseases, where ongoing inflammation or its disorder can be a causative factor or a concomitant process. Although 
some of the molecular pro- and anti-inflammatory mediators may be similar in both of these, resolution of inflammation is disturbed in many chronic diseases. Now we approach the main question. If the patient has an individual inflammatory disorder, e.g. atherosclerosis like in the majority of these patients, is it possible that the aberrant inflammation inside the vessels will be established in posttraumatic local inflammation outside the vessels, too. In that case a small failure in the cooperation of different inflammatory cells, either proportionally, biochemically or both, could become visible as a decreased WICN giving an alarm signal of continuing disease. Presumably the same cells, both normal and abnormal, may act both in- and outside the vessels. Additional support to this hypothesis, based on inflammatory cells in atherosclerosis, was obtained from lower WICN values of patients with coronary heart disease (CHD), corrected with CABG, as compared with non-CHD (valve surgery) patients.

Monocytes are short-lived and do not proliferate in the blood. They accumulate at sites of inflammation, phagocytose other cells and toxic molecules and differentiate into macrophages and foam cells. These again are present in atherosclerotic plaques. The accumulation of macrophages correlates with atherosclerotic plaque progression and plaque rupture [17].

Several of the wound inflammatory cells included in the model for WICN, like neutrophils, lymphocytes, monocytes and macrophages at least, are involved in atherosclerotic plaque formation, too [18]. Hence there is no wonder that inadequate wound inflammation and/or progress of atherosclerotic changes could both have an association with the patients' survival. Normally wound inflammation is highly individual, precisely regulated and well adapted to the demands of ideal wound healing. Deficiencies or excesses in local inflammation may be an early sign of deleterious wound healing itself but even that of the patients' survival.

\section{Acknowledgements}

The authors wish to thank Mr. Kurt Lönnqvist for skillful processing of viscose cellulose sponge and preparing of the Cellstick devices and Ms Satu Sivula, medical laboratory technologist, for precise analysis of the Cellstick specimens. Our sincere thanks are due to the surgeons and personnel at the Department of Surgery for their kind help and collaboration.

\section{Declaration of Interest}

The authors declare no conflicts of interest. The authors alone are responsible for the content and writing of the paper.

\section{References}

[1] Martin, P. (1997) Wound Healing-Aiming for Perfect Skin Regeneration. Science, 276, 75-81. https://doi.org/10.1126/science.276.5309.75 
[2] Diegelmann, R.F. and Evans, M.C. (2004) Wound Healing: An Overview of Acute, Fibrotic and Delayed Healing. Frontiers in Bioscience, 9, 283-289. https://doi.org/10.2741/1184

[3] Eming, S.A., Krieg, T. and Davidson, J.M. (2007) Inflammation in Wound Repair: Molecular and Cellular Mechanisms. Journal of Investigative Dermatology, 127, 514-525. https://doi.org/10.1038/sj.jid.5700701

[4] Thomasson, B., Viljanto, J., Jääskeläinen, A. and Raekallio, J. (1973) EnzymeHistochemical Observations on the Formation of Granulation Tissue in Rabbit Fetuses and Does. Acta Chirurgica Scandinavica, 139, 327-333.

[5] Mast, B.A. and Krummel, T.M. (1992) Acute Inflammation in Fetal Wound Healing In: Adzick, N.S. and Longaker, M.T., Eds., Fetal Wound Healing, Elsevier, New York, 227-240.

[6] Fox, P., Hudson, M., Brown, C., Lord, S., Gebski, V., De Souza, P., et al. (2013) Markers of Systemic Inflammation Predict Survival in Patients with Advanced Renal Cancer. British Journal of Cancer, 109, 147-153.

[7] Savunen, T.J. and Viljanto, J.A. (1992) Prediction of Wound Tensile Strength: An Experimental Study. British Journal of Surgery, 79, 401-403. https://doi.org/10.1002/bjs.1800790508

[8] Odeberg, J., Freitag, M., Forssell, H., Vaara, I., Persson, M.-L., Odeberg, H., et al. (2016) Influence of Pre-Existing Inflammation on the Outcome of Acute Coronary Syndrome: A Cross-Sectional Study. BMJ, e009968.

https://doi.org/10.1136/bmjopen-2015-009968

[9] Tracey, K.J. (2002) The Inflammatory Reflex. Nature, 420, 853-859. https://doi.org/10.1038/nature01321

[10] Nathan, C. and Ding, A. (2010) Nonresolving Inflammation. Cell, 140, 871-882. https://doi.org/10.1016/j.cell.2010.02.029

[11] Laitio, R.P., Viljanto, J.A., Lahti, A., Hurme, S. and Savunen, T.J.A. (2012) Initial Healing of Sternotomy Wounds: Correlation between Preoperative Data and Wound Inflammatory Cell Response. Scandinavian Cardiovascular Journal, 46, 121-126. https://doi.org/10.3109/14017431.2012.659281

[12] Viljanto, J. (1995) A Cellstick Device for Wound Healing Research. In: Altmeyer, P., El-Gammal, S., Hoffmann, K., Hutchinson, J., Eds., Wound Healing and Skin Physiology, Springer, Berlin, Heidelberg, 513-522. https://doi.org/10.1007/978-3-642-77882-7 48

[13] Viljanto, J. and Koski, A. (2011) Neural Network Adapted to Wound Cell Analysis in Surgical Patients. Wound Repair and Regeneration, 19, 162-167. https://doi.org/10.1111/j.1524-475X.2010.00664.x

[14] The Criteria Committee of the New York Heart Association (1994) Nomenclature and Criteria for Diagnosis of Diseases of the Heart and Great Vessels. 9th Edition, Little Brown \& Co., Boston, 253-256.

[15] American Society of Anesthesiologists (2015) ASA Physical Status Classification System. https://my.clevelanclinic.org/

[16] Laffey, J.G., Boylan, J.F. and Cheng, D.C.H. (2002) The Systemic Inflammatory Response to Cardiac Surgery. Implications for the Anesthesiologist. Anesthesiology, 97, 215-252. https://doi.org/10.1097/00000542-200207000-00030

[17] Woollard, K.J. and Geissmann, F. (2010) Monocytes in Atherosclerosis: Subsets and Functions. Nature Reviews Cardiology, 7, 77-86. 


\section{https://doi.org/10.1038/nrcardio.2009.228}

[18] Galkina, E. and Ley, K. (2009) Immune and Inflammatory Mechanisms of Atherosclerosis. Annual Review of Immunology, 27, 165-197.

https://doi.org/10.1146/annurev.immunol.021908.132620

Submit or recommend next manuscript to SCIRP and we will provide best service for you:

Accepting pre-submission inquiries through Email, Facebook, LinkedIn, Twitter, etc.

A wide selection of journals (inclusive of 9 subjects, more than 200 journals)

Providing 24-hour high-quality service

User-friendly online submission system

Fair and swift peer-review system

Efficient typesetting and proofreading procedure

Display of the result of downloads and visits, as well as the number of cited articles Maximum dissemination of your research work

Submit your manuscript at: http://papersubmission.scirp.org/

Or contact ss@scirp.org 